\title{
Use of Storage Water in a Hydroelectric System
}

\author{
J. M. Ukwejeh and B. O. Anyaka \\ Department of Electrical Engineering, University of Nigeria Nsukka
}

\begin{abstract}
Failure to adequately define or understand the use of storage water in hydroelectric system has created a fragmented economic environment and schizophrenia in the industry that has the potential to limit its development as a global industry. This paper suggests that, by redefining the use of storage of water in hydroelectric system as a means of using a decision support system to obtain the efficient use of storage water during low flow. The purpose of hydroelectric system optimization is to maximize the value of water resources by providing rapid and informative recommendations based on current data and dynamic forecasts of hydrology, energy prices and loads at individual hydro plants and within the overall system.
\end{abstract}

Keywords: HydroElectric, Decision-support-System, Optimization, Hydrology,

\section{Introduction}

Hydro means "water". Therefore, hydropower means "water power" and hydroelectric system denote a collection of hydroelectric power plants situated in series along a watercourse and interconnected to formulate a common water-use system. The construction of a hydroelectric system depends on the complete use of the energy resources of water, it increases discharge control which results in increased power and capacity of the hydroelectric plants, and improves the power switching capabilities of individual plants. Since ancient times, hydropower has been used for irrigation and the operation of various mechanical devices, such as watermills, sawmills, textile mills, dock cranes, domestic lifts and paint making.

"Water resources are important to both society and ecosystems. We depend on a reliable, clean supply of drinking water to sustain our health. We also need water for agriculture, energy production, navigation, recreation, and manufacturing. Many of these uses put pressure on water resources, stresses that are likely to be exacerbated by climate change. In many areas, climate change is likely to increase water demand while shrinking water supplies. This shifting balance would challenge water managers to simultaneously meet the needs of growing communities, sensitive ecosystems, farmers, ranchers, energy producers, and manufacturers.

In some areas, water shortages will be less of a problem than increases in runoff, flooding, or sea level rise. These effects can reduce the quality of water and can damage the infrastructure that we use to transport and deliver water" [1].

Most often, we do not consider the initial stages of hydroelectric power. The first step of hydropower is the powers the hydrologic cycle which in turns gives the earth its water. In the hydrologic cycle, atmospheric water reaches the earth's surface as precipitation. Some of the water evaporates, but most of the water is absorbed by the ground and becomes surface runoff. Water from rain and melting snow eventually reaches ponds, lakes, reservoirs, and oceans where evaporation is constantly occurring. This cycle is a never ending cycle and nature ensures that water is a renewable resource. The next step is to generate the electricity. To generate electricity, water must be in motion. When water is in motion, the energy generated is kinetic energy.

When flowing water turns blades in a turbine, the form is changed to mechanical energy. The turbine turns the generator rotor which then converts this mechanical energy into another form of energy - electricity. Since water is the initial source of energy, the collection and storage of water becomes exceedingly important for any hydroelectric system during a period of low flow. Some power plants are located right on a river or canals but for the plants to work at optimum efficiency with a reliable water supply, dams are needed. Dams are used to store water and later release it for purposes such as irrigation, domestic and industrial use, and power generation. The reservoirs are like rechargeable batteries. The water is stored and when power is needed, water is released to generate power. The reservoir is then filled back up with rain and runoff.

The objectives of this study is to use an existing decision support system to allow faster decision making, identification of negative trends, and better allocation of resources all for the efficient use of storage water in a hydroelectric system.

The study highlights best practices and lessons learned from past experiences in the literature review that can help guide efficient and sustainable implementation of storage projects. 


\section{Literature review}

There have been several studies of water reservoir system; Detailed evidence of the use of storage water in hydroelectric system is shown in John D.C Little's study, where "the big water reservoir of hydroelectric system collect water during high river flow for use during low flows". The problem considered in Little's study was to use such stored water in the face of some uncertain flow. Best water use is taken to be that which minimize the expected cost of operating the system. [2].

Tjalling C. Koopmans revealed that John D.C Little "presented a procedure for computing an optimal water storage policy for an electricity generating system consisting of hydroelectric unit (reservoir and generating station) and one or more supplementary thermal station. The latter stations are characterized by an increment cost that increases with the rate of thermal generation". Koopmans found that, the objective of Little's study was to developed and try out a computational procedure that organize uncertainty future water inflow into the reservoir, and to assess the average saving obtainable by a policy of minimizing the mathematical expectation of cost in one particular instance-an approximate model of the grand Coulee plant on the Columbian River. Koopmans pointed out that, while his study borrowed most of its assumption from Little's work, the intent was different as he intends to study the characteristics of an optimal storage policy and to study its dependence on the future paths of water inflow and power demand.

The second purpose of Koopmans study was to "associate with an optimal storage policy imputed values or efficiency prices of the power generated and the water use or in storage, and imputed efficiency rents for the use of hydroelectric generating plants and the reservoir" [3]. He maintained that, these prices and rents are functions of time, and useful in coordinating the operation of hydroelectric and thermal plants, and of different hydroelectric plants on the same or different rivers or river systems [3]. Charles D. D. Howard brings this out with great clarity in his discussion of Hydroelectric System Operations Optimization stressing that, "the purpose of hydroelectric system optimization is to maximize the value of water resources by providing rapid and informative recommendations based on current data and dynamic forecasts of hydrology, energy prices and loads at individual hydro plants and within the overall system. A version of the same software running from a more static database can be used for planning studies and to schedule maintenance. This type of comprehensive optimization software is called a "decision support system" because it recommends quickly how to maximize hydroelectric benefits while meeting non-energy aspects of water management, such as effects on the river downstream and on the fore bay upstream. Decision support systems currently in operation include single generating stations, cascades of dams, and complex river networks" [8].

Charles's paper presents some his experiences with development of decision support systems. This will interest researchers that are planning to develop a decision support system or to update the software currently being used. The objective of decision support systems is to ensure that the best available data are used in an uncompromisingly comprehensive analysis that captures the maximum benefit from the investment in the system of reservoirs and generation facilities. With a properly designed decision support system this goal often can be achieved with little routine effort during day-to-day operations. A decision support system provides an objective method for measuring how well a hydroelectric system has been operated - a valuable component in due diligence investigations when assets are sold or purchased.

Jimsher Giorgobiani et al takes important notice of this in Dynamic Model of Smoothing Problem in Water Power Systems, and offers Mathematical models presented by means of the recurrent equations of a dynamic programming. Jimsher argue that, "The relationship of operational hydroelectric power stations and systems of water reservoirs is studied in this research with the objective of controlling water stores in order to satisfy demand for the electric power with the least expenditures. For any decision period, the share of hydroelectric energy with respect to total energy demand must be established. Hydroelectric energy is assumed to be free-of-charge in comparison with expensive thermal energy. Moreover, because of the specific character of river flow and demand of electric power the problem of providing energy at the least cost is dynamic and stochastic. Many authors, among them [3], investigated the problem of optimal performance of a power system with large number of various power plants by means of the models of mathematical programming. For a single hydroelectric power station this problem under different assumptions was investigated by method of dynamic programming by J. Little [1], S. Karlin [2], J. Gessford [3]. They investigated a problem from the point of view of the theory of optimal control of stores. In this study, we apply the refined method of functional equations to investigate more general problems and to remove some assumptions imposed in the papers cited above" [4].

It can be seen then that differences do exist between some authors in relation to the use of storage water in hydroelectric systems. This can be seen in the assumption made by Little which Koopmans also borrowed from. These assumptions are the bases for which Jimsher et al seek to remove applying refine method of functional equations. In the review, both authors have identified and target different objectives in order to remain at the cutting edge of their findings, but their discussion have been keenly on the efficient use of storage water in hydroelectric systems. Differences between the authors are evident with respect to opinions. 


\section{Methodology}

The understanding and management of the use of water resources in hydroelectric systems is of great value and economic importance as at least half of the world's population depends on hydro power. An innovative methodology for decision-making which can be applied to any decision involving any reservoir system becomes important.

\section{Decision Support Systems}

Problem solving and decision-making are important skills for business and life. Problem-solving often involves decision-making, and decision-making is especially important for management and leadership. There are processes and techniques to improve decision-making and the quality of decisions. Decision-making is more natural to certain personalities, so these organization should focus more on improving the quality of their decisions. Organization or companies that are less natural decision-makers are often able to make quality assessments, but then need to be more decisive in acting upon the assessments made. Problem-solving and decision-making are closely linked, and each requires creativity in identifying and developing options, for which the brainstorming technique is particularly useful.

Good decision-making requires a mixture of skills: creative development and identification of options, clarity of judgment, firmness of decision, and effective implementation. For group problem-solving and decision-making, or when a consensus is required, workshops help, within which you can incorporate these tools and process as appropriate.

According to Eset T. Alemu "Water resources systems are comprised of multiple interdependent environmental, social, hydrological, and administrative units. Their management requires comprehensive and integrated decision making. System wide management necessitates the evaluation of both the needs of different sectors and the conflicting benefits and costs in the region. Improved understanding and management of this intricate and complicated system can be achieved through the construction of a DSS that represents the various aspects of the multipurpose reservoir system" [5]. Our objective in this paper is to utilize a decision making system to illustrate how the best available data are used in an uncompromisingly comprehensive analysis that captures the maximum benefit from the investment in the system of reservoirs.

Figure 1illustrates the components of a comprehensive decision support system developed by Charles Howard \& Associates Ltd. (now Powel Mini-Max) for operations and for planning.

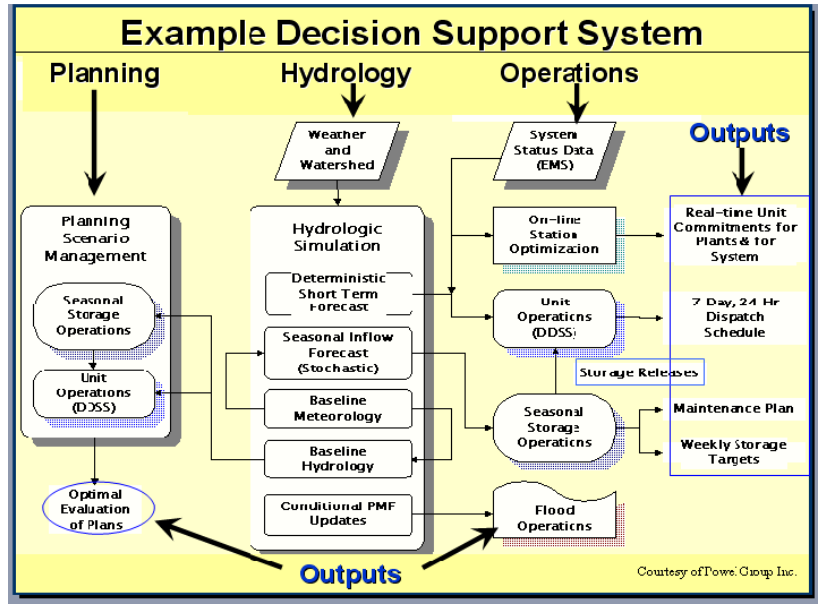

Figure 1 Components of a Comprehensive Hydroelectric Decision Support System [7]

The components of decision support systems depend on how rapidly specific decisions must be made. The properly designed decision support system operations provides an objective method for measuring how well a hydroelectric system has been operated - a valuable component in due diligence investigations when assets are sold or purchased.

Charles's reported that "Short-term hourly schedules provide advice for water management and determine optimal system-wide unit scheduling for generation planning and bidding into the energy market over a weekly cycle. Optimum reservoir storage and release advice depends on mid-term forecasts and targets based on probabilistic optimization over several weeks Short-term hourly schedules provide advice for water management and determine optimal system-wide unit scheduling for generation planning and bidding into the energy market over a weekly cycle. Optimum reservoir storage and release advice depends on mid-term forecasts and targets based on probabilistic optimization over several weeks or more. Maintenance scheduling considers seasonal hydrology, energy prices and loads, and the work crews that are available for tasks of various 
durations. Near-real time (5 minutes) advice within each hydro plant considers unit commitment (which units to run at a given time) and how the units meet the current plant load, or discharge the currently required amount of water, or to determine set points for AGC. Figure 2 is a screen from such a decision support system. The plant performance curve illustrates how load on the hydro system must be allocated carefully to individual dams so their generating units can operate at points that maximize the overall efficiency of each power station" [7].

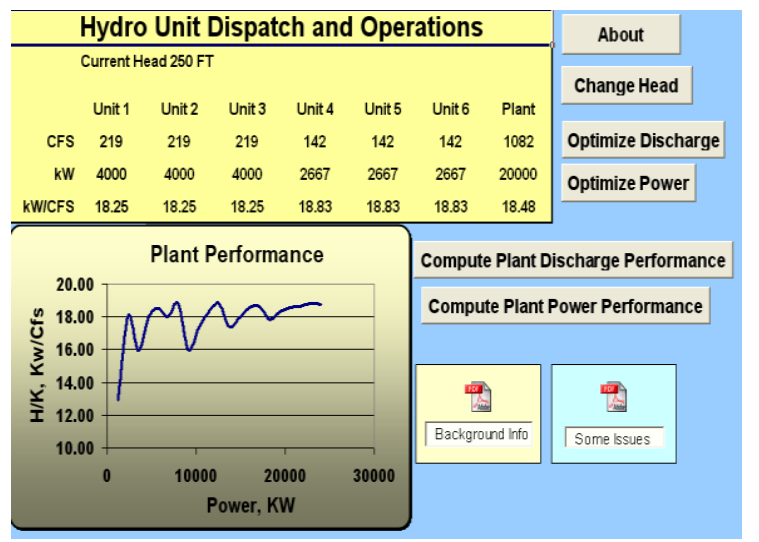

Figure 2 Hydroelectric Plant Operations Decision Support Software[7]

\section{Conclusion}

Many utilities have overcome technical and practical difficulties and have found decision support systems economically efficient and operationally beneficial. Decision support systems should fit within the overall enterprise functioning of the utility. This may include support for performance evaluations, meeting new operational requirements and license conditions, planning for upgrades and new facilities, support for power rate [7].

As this report has shown, with the aid of a good decision support system, the use of storage water in a hydroelectric system can be optimized; "the water management modules optimize the use of storage based on continuously updated deterministic short-term inflow forecasts, and probabilistic long-term inflow forecasts adjusted for current conditions" [7]. When we understand that the best aspect to consider storage of water in hydroelectric system and come to view water storage system as merely that which is used in such a way to minimize the operation cost. This paper charges that the public can rely on decision support system and can be use in water reservoirs of hydroelectric system.

\section{Acknowledgement}

I wish to express my sincere appreciation to my course lecturer who has exposed me to this act of writing and for his fatherly role in reshaping my sense of studies. To my wife Mrs. Gloria Omite James and son Martin Edache Mark who stood in for me while I'm away on studies and for allowing me to use the family resources to go this far. I appreciate the concrete criticizing of my director Engr. Dr. Goshwe N.Y and all my class mate for their invaluable input God bless you all and be with you always.

\section{Reference}

[1]. Water Resources Impacts \& Adaptation: retrieve from http://www.epa.gov/climatechange/impacts-adaptation/water.html

[2]. J.D.C Little, 'The use of storage water in a hydroelectric system,' Journal of the operations research society of America, (1995)

[3]. Tjalling C. Koopmans, 'water storage policy in a simplified hydroelectric system' reprinted from the proceedings of the first international conference on operational research, Oxford (1957)

[4]. C. D. D. Howard, 'Hydroelectric System Operations Optimization' retrieved February $04 \quad 2013$ from www.cddhoward.com/docs/GWREF06-Systems.pdf

[5]. Jimsher G., Mziana N., Weldon A. L. 'Dynamic Model of Smoothing Problem in Water Power Systems' retrieved February 04 2013 from arxiv.org/pdf/0807.0641

[6]. Eset T. A.; Richard N. P.; Austin P.; and Bruce M. 'Decision Support System for Optimizing Reservoir Operations Using Ensemble Streamflow Predictions' retrieved February $04 \quad 2013$ from ir.library.oregonstate.edu/xmlui/handle/1957/23156

[7]. C. D. D. Howard, 'Hydroelectric System Operations Optimization' retrieved February 042013 from www.cddhoward.com/docs/GWREF06- Systems.pdf 